\title{
Evaluación de Dos Tipos de Medios de Contraste para Linfografía Directa en Perro
}

\author{
Evaluation of Two Contrast Media for Direct Lymphography in Dog
}

"Jorge Mendoza A; * Luis Adaro A. \& *Viviana Ojeda

MENDOZA, A. J.; ADARO, A. L. \& OJEDA, V. Evaluación de dos tipos de medios de contraste para linfografía directa en perro. Int. J. Morphol., 25(3):659-662, 2007.

RESUMEN: Se realizó una evaluación de dos medios de contraste para la linfografía directa en 24 caninos mestizos no acondroplásicos, clínicamente sanos. Se utilizó un medio de contraste hidrosoluble (diatrizoato de sodio y meglúmina) y un medio liposoluble (aceite de adormidera yodada), en dosis de $96 \mathrm{mg}$ de yodo por $\mathrm{kg}$ de peso para el miembro torácico y de $192 \mathrm{mg}$ de yodo por $\mathrm{kg}$ de peso para el miembro pélvico. Las imágenes se evaluaron de acuerdo al grado de contraste y definición de las estructuras evidenciables por esta técnica. En ambos medios de contraste el grado de definición obtenido en los miembros y en el sistema colector central fue bueno, sin embargo, se logró un grado de contraste superior con el medio liposoluble, principalmente a nivel de sistema linfático central. Algunos ejemplares evidenciaron la presencia de émbolos pulmonares al usar un medio liposoluble.

PALABRAS ClAVE: Linfografía; Canino; Medio de contraste.

\section{INTRODUCCIÓN}

Las estructuras del sistema linfático no son reconocibles en una radiografía simple, de allí la importancia de aprovechar su capacidad para transportar, almacenar y eliminar sustancias visibles a la radiografía.

La linfografía es el estudio contrastado del sistema linfático que permite la evaluación anátomo-funcional y de procesos patológicos que en él se presentan, así como las variaciones que se pueden establecer entre razas. Alcanzar un dominio de las técnicas de linfografía es importante por el significativo aporte al diagnóstico y pronóstico de patologías del sistema linfático que se observan en la práctica clínica.

\section{MATERIAL Y MÉTODO}

Se utilizó un grupo de 24 perros mestizos, no acondroplásicos, clínicamente sanos, sin distinción de sexo y edad, con un rango de peso corporal de 4 a $15 \mathrm{Kg}$. En 12 de ellos se realizaron linfografías directas con medio hidrosoluble y en el resto, con medio oleoso.
Cada perro fue sometido a un ayuno de 24 horas y para incrementar la formación de quilo se administró por vía oral una dosis de 10 a $30 \mathrm{ml}$, de aceite de maíz ,30 minutos previos a la exposición quirúrgica del vaso linfático.

Los ejemplares fueron premedicados con acepromazina y sulfato de atropina y se empleó un protocolo anestésico en base a tiopental sódico. Se efectuó una incisión de 3 a $4 \mathrm{~cm}$ en la región dorsal al $2^{\circ}$ o $3^{\circ}$ metacarpiano o metatarsiano, para ubicar y aislar el vaso linfático. Luego se inyectó Azul de Evans en el subcutáneo del espacio interdigital del $2^{\circ}$ y $3^{\circ}$ dedo, a fin de lograr la tinción del vascular linfático y así realizar la inyección intralinfática del opaco. La dosis de medio de contraste empleada fue de $96 \mathrm{mg}$ de yodo por kilo de peso para el miembro torácico y 192 mg de yodo por kilo de peso para el miembro pélvico, por ser las dosis efectivas y seguras (Prier et al., 1962; Nishikawa et al., 1983). Se obtuvieron imágenes a los 5 y 15 minutos post inyección del medio de contraste liposoluble en proyección medio- lateral y ántero-posterior y a los 30 minutos las proyecciones ventro-dorsal y látero-lateral de tórax y abdomen. Para el medio hidrosoluble se tomaron las

\footnotetext{
* Departamento de Ciencias Clínicas, Facultad de Ciencias Veterinarias y Pecuarias. Universidad de Chile.

** Departamento de Ciencias Biológicas, Facultad de Ciencias Veterinarias y Pecuarias. Universidad de Chile.
} 
placas radiográficas inmediatamente después de lograda la administración.

En las imágenes obtenidas se clasificó el grado de contraste y definición obtenida en el sistema linfático periférico y central según la nomenclatura anátomo- radiográfica veterinaria, de acuerdo a cada proyección utilizada. En este proceso se emplearon los siguientes grados:

- Buen contraste: Presencia de un trazado claro y contrastado entre estructuras linfática en estudio y tejidos blandos adyacentes.

- Regular contraste: Trazado se presenta poco delimitado y su contraste con tejidos adyacentes es de menor intensidad.

- Escaso contraste: Trazado se hace difícil de evaluar existiendo escasa diferencia entre el sistema en estudio y tejidos circundantes.

Un criterio similar se aplicó al clasificar la definición de imagen.

Los medios de contraste se compararon entre sí de acuerdo a su capacidad de opacificación, definición de estructuras y latencia de imagen en miembros y sistema colector central.

\section{RESULTADOS Y DISCUSIÓN}

El tiempo de permanencia promedio del medio hidrosoluble en el conducto torácico fue de 5 minutos. Esto difiere a lo descrito por Quick \& Jauder en el año 1978, quienes obtuvieron una duración promedio de 16,7 minutos.

En el sistema linfático periférico, el componente canalicular presentó una permanencia promedio del opaco de sólo 3 minutos y el componente de linfonodo de 5 minutos. Debido al lento avance del medio liposoluble hacia el conducto torácico fue necesario, además, obtener imágenes a las 2, 3 y 4 horas post inyección. Las radiografías obtenidas a los 5 y 15 minutos mostraban la presencia de opaco sólo en los linfonodos poplíteos, a los 30 minutos se observaba en los linfonodos ilíacos externos y a las 2 y 3 horas en la cisterna del quilo y a las 4 horas en el conducto torácico. El tiempo de permanencia del medio liposoluble en los nodos linfáticos fue superior a 72 horas, lo que corroboraría lo expuesto por Goldberg \& Feinberg (1963), Schaffer et al. (1963) y Quick \& Jauder en el sentido que es posible observar nodos contrastados varios días después de una linfografía con medio liposoluble.
El grado de contraste logrado con medio de contraste hidrosoluble en el linfonodo cervical, fue mayoritariamente regular para el medio hidrosoluble, en cambio para el liposoluble fue bueno. En referencia al grado de definición, se observó una buena calidad en ambos casos.

En el linfonodo axilar, en ambas proyecciones, el grado de definición y contraste fue malo para los dos tipos de opacos. Esta situación se debería a la existencia de vasos aferentes que provienen de otras regiones como la pared torácica y de estructuras profundas del miembro toráxico (Miller et al., 1965).

El linfonodo poplíteo evidenció mayoritariamente un buen contraste y definición, indistintamente del medio de contraste empleado y la proyección. A nivel del linfonodo sacro lateral se estableció una escasa visualización para ambos medios de contraste. Esta situación se debería a que el $50 \%$ de los caninos carecen de este linfonodo y cuando lo presentan, reciben aferentes provenientes de la región ventral del sacro (Miller et al.)

En el linfonodo iliaco externo es posible establecer diferencias referentes al contraste y definición que para el medio de contraste liposoluble fueron superiores respecto a lo observado para el medio de contraste hidrosoluble, en ambas proyecciones.

El conducto torácico y la cisterna del quilo, fueron observadas sólo en la proyección lateral de tórax debido a la superposición que ejerce la columna dorsal. No se observó la cisterna del quilo en proyección ventral debido a la superposición de la columna vertebral.

El conducto torácico en proyección ventral no se observó al utilizar un medio hidrosoluble. Con un medio liposoluble se observó sólo una vez con regular contraste y definición. Esto también se explicaría por la superposición de la columna vertebral.

Un caso presentó múltiples nodulaciones a través del recorrido de los vasos linfáticos del miembro pélvico hasta la zona de los canales aferentes del linfonodo ilíaco externo.

Se evidenció una notable variación individual en lo referente a tamaño, forma y número de los nodos linfáticos, como también de sus aferentes y eferentes, lo que corrobora lo expuesto por Kagan \& Breznock (1979) y Prier et al. A pesar de esta variación todos los nodos aparecieron densos y homogéneos observándose, además, a nivel femoral, un confluente linfático formado por los eferentes del linfonodo poplíteo, en los 24 casos en estudio. 
Fig. 1. Radiografía L - L de tórax. Se observa la presencia de medio de contraste liposoluble en el linfonodo cervical superficial, destacando además la existencia de embolia a nivel venoso pulmonar.

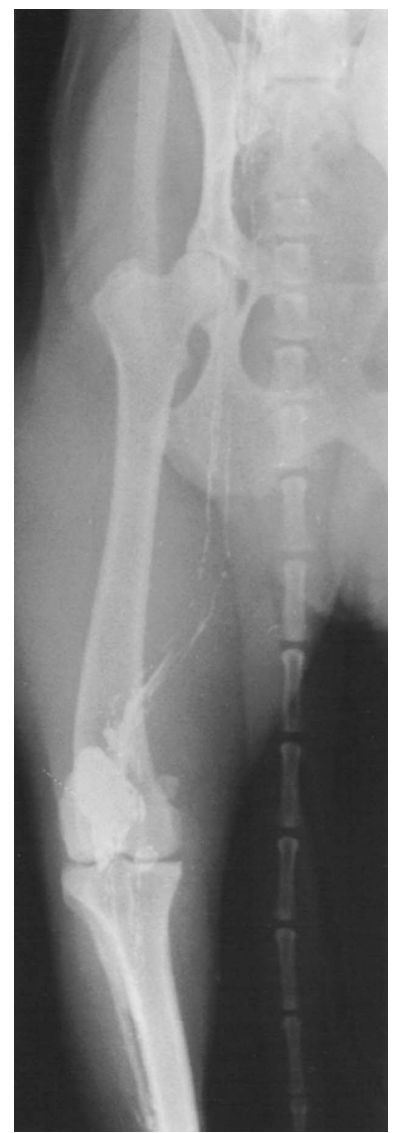

Fig. 2. Radiografía A - P de miembro posterior derecho. Se evidencia la presencia de medio de contraste liposoluble en forma segmentada en conducto linfático aferente, la imagen demarcada del linfonodo poplíteo y posterior demarcación de dos conductos eferentes que se dirigen hacia el linfonodo ilíaco externo.

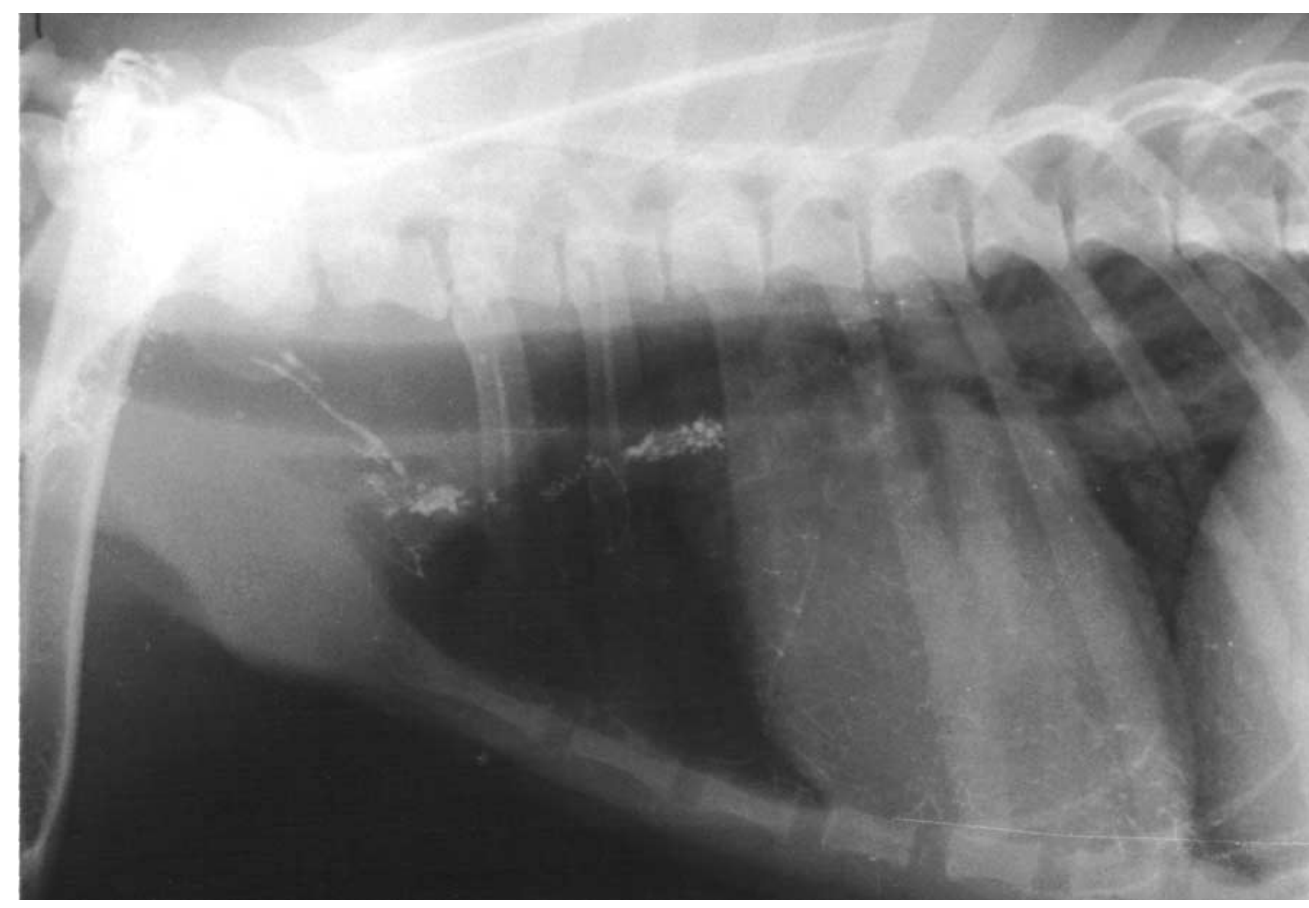

En 4 ejemplares se observó la presencia de linfangiectasia, aún cuando los caninos se presentaban clínicamente sanos.

En tres casos donde se utilizó medio de contraste hidrosoluble, se evidenció una urografía de excreción observándose contrastada la vejiga urinaria. Éste se debería a la incorporación del medio de contraste a la circulación venosa y por la presencia de anastomosis linfático venosas según lo descrito por Kagan \& Breznock y su posterior excreción renal por filtración glomerular Agut et al. (1992).

Los resultados obtenidos con el medio liposoluble, en cuanto a grado de contraste de la imagen, fueron superiores a los proporcionados por el medio hidrosoluble, especialmente a nivel del sistema linfático central ya que el conducto torácico sólo se observó en 4 casos al usar un medio hidrosoluble, mientras que al usar un medio liposoluble se evidenció en 10 de 12 casos. Esto difiere a lo expuesto por Quick \& Jauder y por Kagan y Breznock, quienes obtuvieron mejores resultados en el contraste del conducto torácico.

MENDOZA, A. J.; ADARO, A. L. \& OJEDA, V. Evaluation of two contrast media for direct lymphograhy in dog. Int. J. Morphol., 25(3):659-662, 2007.

SUMMARY: Two contrast media for direct lymphography in 24 healthy dogs not achondoplasic were evaluated. It used a hidrosoluble contrast media (sodium diatrizoato and meglumina) and another lyposoluble media (Ionided adormidera's oil) in dose of $96 \mathrm{mg} / \mathrm{I} / \mathrm{kg}$ to the thoracic member and $192 \mathrm{mg} / \mathrm{I} / \mathrm{kg}$ for a rear member. The images were evaluated indeed of contrast level and definition of structures for each contrast media. The definition degree for each contrast media both the members and central collector system were good, however its was better for the lyposoluble contras media, especially in the central collector system. Some dogs show embolous in the lungs vessel when lyposoluble media was used.

KEY WORDS: Lymphography; Dog; Contrast media. 


\section{REFERENCIAS BIBLIOGRÁFICAS}

Agut, A.; Sánchez-Valverde, M. A.; Lasaosa, J. M. \& Laredo, F. G. Radiodiagnóstico de pequeños animales. $1^{\text {a }}$ ed. español, Interamericana, Madrid, 1992. pp 67-82.

Goldberg, M. E. \& Feinberg, S. B. Pulmonary infarction following lymphangiography in dogs: its implications in human studies. Radiology, 81:479-83, 1963.

Kagan, K. C.; Breznock, E. M. Variations in the canine thoracic duct system and the effects of surgical occlusion demostrated by rapid aqueous lymphography, using an intestinal lymphatic trunk. Am. J. Vet. Res., 40: 948 -58. 1979.

Miller, M. E.; Evans, H. E.; Christiesen, G. C. Anatomy of the dog. 2ed. Baunders Company, Philadelphia, 1965. pp. 430-63.

Nishikawa, Y.; Tachibana, F.; Kudo, T.; Otomo, K. \& Koike, T. Experimental studies on lymphography in dogs. Clinical and hematological findings following lymphography of pelvic limbs. JPN. J. Vet. Se., 45:2817, 1983.

Prier, J.; Schaffer, B.; Skelley, J. Direct lymphangiography in the dog. J. Am. Vet. Med. Assoc., 140: 943-7, 1962.

Quick, CH. B. \& Jauder, H.P. Aqueous lymphangiography of the canine thoracic duct. Vet. Radiology, 19:178-80, 1978.

Schaffer, B.; Koehler, P. R.; Daniel C. R.; Wohl, T.; Rivera, E. Meyers, W. A.; Skelley, J. F. A critical evaluation of lymphangiography. Radiology, 80:917-28. 1963.
Dirección para correspondencia:

Dr. Jorge Mendoza Antúnez

Profesor de Radiología Veterinarias

Facultad de Ciencias Veterinarias y Pecuarias

Universidad de Chile

Santa Rosa 11735

La Pintana

Santiago - CHILE

Email: jomendoz@uchile.cl

Recibido : 08-06-2007

Aceptado: 12-07-2007 